\title{
Global challenges of implementing human papillomavirus vaccines
}

\author{
Janice E Graham ${ }^{1 *}$ and Amrita Mishra $2^{2^{*}}$
}

\begin{abstract}
Human Papillomavirus vaccines are widely hailed as a sweeping pharmaceutical innovation for the universal benefit of all women. The implementation of the vaccines, however, is far from universal or equitable. Socioeconomically marginalized women in emerging and developing, and many advanced economies alike, suffer a disproportionately large burden of cervical cancer. Despite the marketing of Human Papillomavirus vaccines as the solution to cervical cancer, the market authorization (licensing) of the vaccines has not translated into universal equitable access. Vaccine implementation for vulnerable girls and women faces multiple barriers that include high vaccine costs, inadequate delivery infrastructure, and lack of community engagement to generate awareness about cervical cancer and early screening tools. For Human Papillomavirus vaccines to work as a public health solution, the quality-assured delivery of cheaper vaccines must be integrated with strengthened capacity for communitybased health education and screening.
\end{abstract}

Keywords: Human Papillomavirus, cervical cancer, vaccine, immunization, equity, gender

\section{Introduction}

In 2006, Gardasil ${ }^{\circledR}$ or Silgard ${ }^{\circledR}$ (Merck), an adjuvanted vaccine against four Human Papillomavirus (HPV) types, was licensed for market in the Gabon, followed by the US, Canada and more than 100 other countries [1].(See additional file 1: appendix) Initial recommendations for use of Gardasil ${ }^{\mathbb{R}}$ in Canada and the US included precoitarchal 9-13 year-old females and 14-26 year-old females even if already sexually active, with a history of cervical abnormalities or prior HPV exposure [2,3]. The vaccine was not recommended for females who were pregnant or less than 9 years of age. For women older than 26 years, immunization could be considered according to individual circumstances. In May 2007, another HPV vaccine, Cervarix ${ }^{\text {TM }}$ (GlaxoSmithKline) became available in Australia for females aged 10 to 45, in September 2007 in the European Union (EU) and in the US in 2009 for females aged 10 to 25 [4-6]. In 2009, the U.S. Food and Drugs Administration (FDA) licensed

\footnotetext{
* Correspondence: janice.graham@dal.ca; amritamishra1973@yahoo.co.uk + Contributed equally

${ }^{1}$ Department of Bioethics, Dalhousie University, Faculty of Medicine, 1459 Oxford Street, Halifax, Nova Scotia, B3H 4R2, Canada

${ }^{2}$ Technoscience and Regulation Research Unit, 1459 Oxford Street, Halifax,

Nova Scotia, B3H 4R2, Canada

Full list of author information is available at the end of the article
}

the use of Gardasil ${ }^{\circledR}$ for 9-26 year-old males against genital warts caused by HPV 6 and 11 [7].

Gardasil $^{\mathbb{B}}$ and Cervarix ${ }^{\mathrm{TM}}$ are prophylactic vaccines for the primary prevention of HPV types 16 and 18 (implicated in 70 per cent of cervical cancers). Additionally, Gardasil ${ }^{\circledR}$ protects against HPV types 6 and 11 (implicated in genital warts, which are non-lethal but painful and hard to treat) [8-10]. A 3-dose intramuscular administration (currently costing approximately US\$ 360) at 0, 1-2 and 6 months is required [6]. The vaccines generate a relatively robust immune response against targeted HPV types in 15-25 year old females who are pre-coitarchal and/or DNA and serologically negative for the targeted HPV types $[11,12]$. For both vaccines, the immune response in older women (25-45 years) is stronger than natural infection levels but less than that in 9-15 year olds [13,14].

HPV vaccines have been formally recommended, although not uniformly adopted, for large-scale use in the public sector healthcare systems and national immunization programmes of the wealthier countries of Europe, North America and Australasia [1,15,16]. In developing countries, however, HPV vaccines are not available through national immunization programs. (Following the usage of the International Monetary Fund, and in the absence of other established naming conventions, we

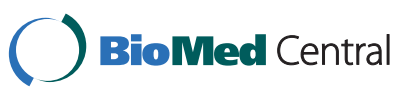


apply the term "developing country" to emerging and developing economies [17].) Cost is a leading barrier to equitable delivery of HPV immunization in developing countries, where limited health budgets must address multiple contending priorities [18]. The high vaccine cost can be linked to the monopoly pricing power of vaccine manufacturers seeking to recover high development costs. Their retention of exclusive patent rights and their power to keep vaccine prices high are aided by the absence of compulsory licenses, which could authorize the competitive development of cheaper biogenerics through developing country manufacturers [19-21]. Public sector funding, the aid of vaccine funding consortia such as the Global Alliance for Vaccines Initiative (GAVI), and suitable technology transfer mechanisms are crucial to make HPV vaccines available at affordable prices in developing countries [19-21].

\section{Analytical approach}

Taking a science studies approach, we regard vaccines as socio-technical objects that have technical, cultural, historical, economic, geo-political, and ethical dimensions [22]. While vaccination is a technical means to achieving immune protection against disease, immunization encompasses technical means and socio-political settings, actors, plans, objectives and results. Thus, through this paper, we adopt the term 'immunization' in preference to 'vaccination.'

Furthermore, we draw on the Erickson-DeWals-Farand analytical framework to examine the implementation of HPV vaccines [23]. That framework suggests that the inclusion of a vaccine in a publicly funded immunization program requires consideration of both technical and social factors, and of their interrelationship. These factors include disease burden, vaccine efficacy, safety, and immunogenicity, absolute cost and marginal cost-effectiveness ratios, immunization strategy, implementation feasibility, delivery resources, and dose schedules, and equally important, public knowledge and acceptance, and the political implications of immunization strategy, such as mandatory or elective immunization [23]. HPV immunization exemplifies vaccine politics. It not only activates debate on gender, freedom, safety, responsibility and management of adolescent sexuality, but also raises questions surrounding equity in delivering new vaccines to the world's poorest regions.

While the Erickson-DeWals-Farand framework was developed for the Canadian context, we extend its scope to examine the challenges for HPV vaccine implementation, particularly in developing countries. Vaccines are transnational commodities, subject to national and international regulatory decision-making related to standards of safety, efficacy and quality. As with all health technologies, however, vaccines are not created or distributed equally. Diseases endemic in developing countries remain under-researched. Even when effective preventions and therapies are discovered, they are often unavailable to people in developing economies, including those in highincome countries. HPV immunization is a case in point. Currently, developing countries bear about 80 per cent of the global mortality from cervical cancer, i.e., an estimated 242,000 compared to 33,000 deaths in highincome countries [24-26]. Given the gaps in secondary prevention, HPV immunization would seem the obvious intervention to control mortality from cervical cancer in developing countries. Unfortunately, the implementation of HPV vaccines in resource-poor regions faces not only the barriers of vaccine cost, competing health priorities, and public acceptance, but also the systemic lack of infrastructure that inhibits secondary prevention through cervical screening. Further, lack of awareness and social restrictions on gynecological examination prevent women from accessing screening services when available.

\section{The challenges of secondary prevention}

In this section, we elaborate on the infrastructure and social barriers to secondary prevention of HPV-related disease. These gaps are persistent and will continue to hamper immunization strategies, even when HPV vaccines are made readily available in developing countries.

Of the over-100 classified genotypes of HPV, over 40 types can infect the upper respiratory-digestive tracts and anogenital areas. In most cases, HPV infection is cleared or becomes undetectable, causing no disease; however, persistent HPV infection is causally related to the development of cancers and genital warts. Over 99\% of cancers of the uterine cervix are attributed to persistent infection by HPV 16, 18, 31, 33, 35, 39, 45, 51, 52, $56,58,59,66$ and 68 , in that order of frequency. HPV is also associated with external genital warts, respiratory papillomatosis, and head, neck, anal, penile, vulvar and vaginal cancers [27-31].

Cervical cancer is generally marked by a long latency period, during which lesions progress through identifiable stages to invasive growth. Secondary prevention involves screening of asymptomatic women for detection, triage, management and monitoring of precancerous abnormal cells and atypical squamous cells of undisclosed significance (ASCUS). Screening methods include conventional cytology (Papanicolaou or 'Pap' smears, microscope examination of slide-mounted cervical cell samples), Liquid-Based Cytology (LBC), Visual Inspection with Acetic Acid (VIA), Visual Inspection with Lugol's Iodine (VILI), and more recently HPV DNA tests for triage of women with ambiguous cytology to colposcopy or for surveillance of women older than 30 years for the presence of high-risk HPV DNA $[32,33]$. 
Although there is still no treatment for HPV, since the 1950s, cytologic screening has been a key tool in prevention of cervical cancer. In high-income economies, organized programs for screening and post-screening treatment have reduced morbidity and mortality from cervical cancer through standardised systems of screening, monitoring, and recall-and-reminder [24-26,32-34]. Resource-poor settings in developing countries, however, often lack primary physicians, screening equipment (e.g., colposcopes), trained laboratory personnel (e.g., cytotechnicians), and necessary expertise and capacity for screening quality assurance [34]. The lack of effective screening programs is often combined with inadequate knowledge about cervical cancer (causes, symptoms, progression and treatment), even among healthcare workers [35]. In emerging economies (e.g. Malaysia) and high-income Asian economic regions (e.g. Hong Kong), cervical screening can still be hampered by embarrassment surrounding sexually transmitted infections (STI) and gynecological examination, as well as inadequate awareness about HPV-related risks and protections [36,37].

Even in high-income countries, availability of screening services does not always translate into accessibility for socioeconomically marginalized and vulnerable girls and women. In Canada, the US, the UK, and Australia cervical cancer is higher among indigenous and minority women, who experience the health effects of poverty, inadequate insurance, linguistic barriers, insufficient knowledge of health needs and risks, lack of trust in health services, and shame regarding gynecological consultations (conversation) and examination [38-45].

The labor-intensive assessment of Pap smears is associated with false negatives and low sensitivity, which require women to repeat the test. The American Congress of Obstetricians and Gynecologists (ACOG) recommend that screening start at age 21 , to be repeated once every 2 years until age 30 and then every 3 years until 65-70 [46]. Despite repeated efforts to standardize cytologic reporting guidelines and screening practice, there are knowledge gaps and disagreements over the management of patients, in particular those with ASCUS and low-grade lesions, care for women older than 65 years, and the effects of HPV immunization on screening initiation and intervals [47-51].

Screening repeats demand follow-up compliance, which is a particular challenge in remote impoverished rural areas, where women must schedule time away from necessary daily tasks (such as herding, fetching water or firewood) or travel long distances to clinics to be tested. Ensuring compliance requires maintaining screening registries and establishing mechanisms for reminders and follow-ups that do not provoke anxiety or cause embarrassment among women [52]. Inadequate networks, personnel and expertise inhibit public education, disease surveillance and follow-up monitoring in resource-poor settings.

The implementation of the other screening methods also faces challenges. Although HPV testing is less affected by subjectivity or artifact than cytology, it requires more laboratory facilities, costs more than Pap tests, and can be difficult to accomplish in developing countries. Further, HPV testing has higher sensitivity but lower specificity than cytology, implying fewer false negatives but increased false positives and over-triaging to colposcopy. This can increase resource demands on healthcare and anxieties and physical burdens for patients. Although new and cheaper HPV tests are being developed, they are not yet available for widespread use in developing countries [53-55]. Although LBC allows a combination of cytology and HPV testing, cytology itself remains error-prone. Inexpensive visual screening procedures such as VIA and VILI are easier to implement in developing settings and local health workers can be trained to do them. The procedures, however, lack guidelines and the readings are highly subjective, error-prone and not easily reproducible [56].

Women in remote rural areas are at greater risk of cervical malignancies because they have limited access to cervical screening and appropriate treatment. Further, they frequently present for the first examination with late stage malignancies and co-morbidities such as malnourishment, anemia, malaria and HIV/AIDS [57-59]. In developing countries, the resource limitations of medical services, including oncology, constrain 'structure' (the capacity of the medical system to manage disease). Structural limitations constrain 'access' (availability, spatial accessibility, affordability, accommodation, acceptability, and awareness) and negatively impact 'process' (the quality of care from entry to discharge, and post-discharge) and 'outcomes' (the effects of medical intervention on survival, quality of life, patient awareness and behavior) [60].

Late presentation and the lack of therapeutic options (e. g., cryotherapy or loop electrosurgical excision for cervical intraepithelial neoplastic lesions; cold knife conization and simple to radical hysterectomy for micro-invasive cancers; irradiation and/or chemotherapy for more advanced stages) probably explain the observed 5-year survival rates of less than 25\% in Uganda and Zimbabwe. This is in contrast to $60-75 \%$ survival rates in high-income countries. Women may be ashamed of or resigned to their condition. They may not obtain or complete available treatment because of stigma associated with hysterectomy or the fear of hair loss, for example, from chemotherapy [60,61].

\section{Vaccine rhetoric: Unpacking the claims}

Although HPV immunization has the potential to address the challenges of screening, a number of social and policy barriers still prevent its implementation as a 
public health solution in developing economies. Public awareness, for example, would facilitate both primary and secondary prevention by tackling issues such as embarrassment surrounding STIs and the public reception of HPV immunization. Vaccines are most often given to healthy, young (immunologically naïve) individuals. The administration of a vaccine is invasive, can be painful, and has the potential of adverse events; harms and benefits must be weighed. Efforts to communicate and exchange information could promote acceptance and uptake. Commercial rhetoric, however, has taken precedence over public health education about $\mathrm{HPV}$, its related diseases, and the prophylactic effects and limitations of HPV vaccines.

Rhetoric has played a major role in industry marketing and how the entire range of stakeholders, including industry, scientists, health care providers and the public, view the vaccine and HPV implementation. The HPV vaccine has become a contested object where industry advertising and profit motives have pre-empted its public health value.

Mandatory HPV immunization has been criticised as a violation of parental autonomy for the prevention of a non-casually transmitted infection, a misuse of taxpayers' money for a vaccine of unknown effectiveness at the expense of more pressing public health issues, an unnecessary addition to overloaded vaccine schedules, a promotion of teenage promiscuity, and a devaluation of abstinence messages. Mandatory immunization supporters argue that abstinence is ineffective in protecting against STI, that secondary prevention of cervical cancer has irremediable gaps, that there are already mandates for Hepatitis B Virus (HBV) immunization, and socio-economically vulnerable women must be protected against cervical cancer [62-64].

HPV vaccines are marketed as a women's right, choice and duty for health security, exemplified in the Gardasil 'I choose' commercials $[65,66]$. Socioeconomic realities pose barriers to access and choice, however, for immunization and screening [67]. Additionally, HPV and cervical cancer affect the families and social and economic networks of women who succumb to the disease because they lack access to both prevention and treatment. The advertising around HPV vaccines conflates HPV infection, which is widely prevalent and easily transmitted, with cervical cancer, which is "a relatively rare consequence of a common infection" [68: 365]. On occasion, the scientific literature tends to equate HPV immunization with the 'end of cervical cancer' $[69,70]$.

Pharmaceutical advertising of the so-called 'cervical cancer vaccine' resonates with an operative dilemma for public health 'social marketing': Is the acceptability of the vaccine improved by presenting it as 'anti-cancer', instead of 'anti-STI' [71]? On the one hand, Gardasil receives high acceptance from parents who wish to protect the health of their children. On the other hand, parents worry that their children may interpret their acceptance of the vaccine as approval of sexual activity. Parents are concerned that their children may see HPV immunization as blanket protection against the effects of sexual risk-taking. Parents who reject the vaccine may believe that their children's 'safe' or 'moral' behavior is adequate protection against STI. In the absence of balanced public health information, media reportage has stoked community concerns about the effects of HPV vaccines on teen behavior [9,72-76]. In the public health perspective, health is a public good rather than a means for profit. The public funding, delivery and allocation of a vaccine are informed by the idea of immunization as a public good. The public profile of the $\mathrm{HPV}$ vaccine has been undermined by infomercials that create the impression of a personalized 'drug against risk,' an object for commercial profit and consumer desire, separate from public health considerations of community, equity, and accessibility $[65,77]$.

The high cost of the vaccine has compelled public payers to ration its subsidization to unexposed adolescent females with the expectation that high uptake will build herd immunity. This has resulted in HPV, HPV-related disease, and HPV vaccine being marked as 'women-only,' despite the fact that men also get and transmit the virus. The prescription of 'HPV immunization for girls' to ensure 'herd immunity' suggests that HPV is an exclusively heterosexual concern. HPV also affects lesbian, gay, bisexual and transgender (LGBT) people. HPV vaccine commercials and public health messages focus on cervical cancer, to the exclusion of throat, anal and penile cancer [78]. Despite the reported prevalence of oncogenic HPV type 16 in anal HPV infection, anal Pap smears are hindered by silence, homophobia, lack of awareness, fear of stigma, and unaddressed technological gaps [78]. Even in many highincome countries, LGBT people may not seek sexual health advice, or screening services due to fear of outing and its consequences [79].

Focus on school-based immunization of preadolescent girls removes attention from the risk faced by older women from invasive disease due to persistent HPV infection [30]. In Canada and the US, women above 26 years of age are not vaccine eligible $[2,3]$. Women in lower socioeconomic brackets would not be able to pay for the vaccine at its current cost. Funding for cervical screening programs for older, socioeconomically vulnerable women should be strengthened. Exclusive strategic focus on HPV immunization for younger women should not weaken attention to the health needs of older women.

It will take at least 20 years of targeted immunization of adolescent cohorts before there is a measurable reduction in cervical cancer incidence [14]. In the short term, HPV immunization may affect screening for 
precursors to invasive disease $[14,80,81]$. Cytologists may need re-training to accommodate new sensitivity and specificity from higher rates of negative slides per number viewed. HPV tests, if available at lower prices, may prevent harms from reduced cytologic accuracy. The creation and integration of immunization and cancer registries would facilitate monitoring of disease and vaccine effectiveness, identification of vulnerable populations (mapping vaccine uptake and high-risk behaviour), and the possible revision of screening guidelines [82-84]. Even in well-resourced settings, however, privacy laws and issues related with transferring records from paper to electronic formats may hamper surveillance [85]. These problems are exacerbated in developing countries without the infrastructure or capacity for adequate population health monitoring and databases.

\section{Comparing Hepatitis B and human papillomavirus immunization}

The clinical efficacy of both HBV and HPV vaccines is in their ability to block the acquisition of viruses that are transmitted through non-casual intimate physical contact (with HBV additionally blood-borne) $[28,68,86]$. Realworld effectiveness, however, is in the prevention of acute and chronic conditions and cancers induced by persistent viral infection, e.g., fulminating hepatic necrosis, chronic infection with liver failure and primary hepatocellular carcinoma from HBV and papillomatosis and oropharyngeal and anogenital carcinomas from HPV [27-31,68,86]. The clinical effectiveness of a vaccine dovetails with cost-effectiveness when it is delivered to populations with the greatest burden of disease. In this area, HBV immunization has fared better than HPV immunization and illustrates the important role of multilateral partnerships in making new vaccines available to vulnerable populations in developing countries.

At the time of introduction, both vaccines have raised concerns about cost, cost-effectiveness, public acceptability, and priority for public health [86,87]. A combination of factors made the initially expensive HBV vaccine (around US\$ 100 during the early 1980s-1990s) available for use in childhood immunization programs in developing countries [86]. These factors included technology transfer for manufacturing a cheaper biogeneric at US\$ 1.00 per dose, feasibility demonstration projects of the International Task Force on Hepatitis B Immunization, and the intervention of GAVI to make the vaccine available in eligible countries [86]. In 1994, the World Health Organization (WHO) incorporated $\mathrm{HBV}$ vaccine into the Expanded Program on Immunization (EPI).

GAVI may be able to subsidize HPV vaccines for delivery in the poorest countries, provided vaccine manufacturers sell the vaccine to GAVI at lower prices [88]. This process involves several stages: first, the vaccine price reduction for country purchase; second, GAVI Board approval for vaccine funding, conditional on availability of funds; and finally, decision-making by GAVI-eligible countries on the inclusion of HPV vaccine in national immunization programmes [88]. Without cost reduction, HPV vaccine cannot be offered for 9-13 year-olds through the WHO EPI program, which provides the infrastructure and public trust to have some success [35]. Such programs are not available in many emerging economies. Thus, although some individuals may be able to purchase the vaccine, it remains out of reach to most vulnerable women.

In the US, HBV vaccine mandates have been passed, delivering an otherwise expensive vaccine to children prior to their school entry. A comparison of the differing histories of HBV and HPV vaccines in the US illustrates the importance of institutional credibility, dialogue, and regulatory decisions related to licensing and implementation.

It took seven years for the HPV vaccine to go from FDA approval in 1986, to the US Advisory Committee on Immunisation Practices (ACIP) recommendations in 1991, to mandated requirement for day care attendance, in 1993. This time, along with its cost-reducing inclusion in the Vaccines for Children (VFC) program in 1994, provided the opportunity for the public to become aware of HBV immunization and accept its mandate [89]. In contrast, the rush to mandate Gardasil in 2007 (Texas, subsequently overturned) after its 2006 licensing, accompanied by an aggressive marketing campaign, attracted criticism and controversy. The intrusion of pharmaceutical interests into health policy was suggested [64,89-91]. This speed contributed to suspicions rather than building public awareness and acceptance of HPV immunization. After much legislative debate in several US states, only Virginia and the District of Columbia passed HPV mandates, with extensive opt-out provisions [89,91].

Immunization against HPV, unlike that against HBV, specifically and conspicuously targets female adolescents [92]. Socially entrenched anxieties about female sexuality are activated to a greater extent and influence the public reception of HPV immunization [62,63]. These views should be debated through a free and, if necessary, even protracted, exchange of views and information. Accelerated vaccine rollouts, regardless of intention, limit the possibility of debate and exchange of views.

\section{From laboratories to people: Complex itineraries for HPV vaccines}

The successful development and market authorization of vaccines do not in themselves realize the public health purposes of immunization. A vaccine, no matter how innovative and efficacious, serves public health only if it is a safe, affordable, accessible and cost-effective intervention. There are multiple barriers to making HPV 
vaccines available for use in medically-underserved developing, economies. In general, the delivery of vaccines in developing countries faces a wide range of socio-technical challenges that include lack of institutional capacity for monitoring of pre-market vaccine quality and safety and post-market surveillance for adverse events following immunization (AEFI), cold chain difficulties in vaccine delivery to populations in remote rural areas, risk of infection during needleadministration, and fear of needles [23]. With HPV vaccines, there are other, specific challenges.

As discussed, the availability of HPV vaccines in developing countries is particularly hampered by high vaccine costs, bottlenecks of technology transfer for developing cheaper subsequent entry vaccines, low acceptability of vaccines against STI for pre-adolescents, and the problems of integrating HPV vaccines into the formularies of country EPIs [19-21]. These challenges are summarized in Table 1. For policy makers in developing countries, the prevention of a disease that manifests years in the future has less political urgency than the immediate prevention of conspicuous diseases such as poliomyelitis, tuberculosis, or HIV/AIDS. For an individual, hunger and inadequate shelter trump concerns about a silent, slow-developing cancer. The risk-benefit profiles that drive health decision-making in a well-off economy do not apply in contexts where political violence, forced migration, epidemics (e.g., cholera, meningitis), drought, floods, crop failure, and starvation threaten daily survival. Despite promising clinical data, questions persist about immunogenic duration and the need for boosters on HPV vaccine effectiveness [93]. These issues have significant cost-effectiveness implications for poorer individuals, communities, and countries. The currently available vaccines target 16 and 18, two of the 15 most prevalent high-risk HPV types. Among the types not targeted, HPV types 45 and 31 are prevalent, respectively, in sub-Saharan Africa and Central/South America. The development of effective multi-antigen HPV vaccines, however, may be challenged by cross-reactivity between included antigens [27]. The early age of immunization ( 9 years for $\operatorname{Gardasil}^{\circledR}$ ) also remains contentious. Despite clinical data that supports targeting unexposed recipients, parental beliefs about the appropriateness of pre-adolescent immunization limit the uptake of HPV vaccines among pre-teens. Vaccine decisions are made not only by designated policy-makers but also by the public, whose knowledge, attitudes and beliefs (KAB) are key factors in vaccine acceptance. Consistently, across a wide range of countries and ethnicities, KAB studies report socio-cultural barriers to HPV vaccines. These include lack of awareness about HPV effects and protections, parental and physician unwillingness to vaccinate or to discuss sex and STI with preadolescent females, concerns about vaccine costs and uncertain duration of effectiveness, fear of unethical motives and practices in vaccine trials, fear of needle pain, adverse effects (e.g., infertility and physical disfigurement), socially unacceptable vaccine ingredients (e.g., alcohol, a concern for Muslims), stigma and sexual disinhibition [94-110].

Uncertainties and fears associated with unknown substances in the vaccine can discourage some. Rumors of adverse (or rumoured deliberate) effects, such as sterilization, led to the failure of polio vaccine initiatives in northern Nigeria [111]. A 3-dose HPV vaccine schedule poses compliance burdens. Information written in a vaccine booklet is not accessible to women without literacy. Further, keeping a vaccine booklet intact and legible may be a problem for those living in huts with termites and leaking roofs [112].

Even if inexpensive HPV vaccines could be developed, manufactured, subsidized and supplied with quality assurance, parents may not always accept immunization of their pre-adolescent children for an STI [71]. Challenges of knowledge translation that have hampered efforts to promote cervical screening may carry over to HPV immunization. For instance, in a Hong Kong study of attitudes to HPV immunization, Chinese participants thought that HPV caused disease of the nipple, because the Chinese characters used for HPV translated as 'breast' or 'nipple' [95]. Misunderstandings such as these can hamper both the perceived need for health protections and efforts to obtain them. Physicians, who play a key role in knowledge exchange and uptake of health protections, report confusion about HPV, HBV, Herpes Simplex virus (HSV), and Human Immunodeficiency Virus (HIV) $[113,114]$. KAB studies demonstrate the absence of a reliable body of publicly accessible information on cervical cancer and its link to HPV. Individuals may not perceive themselves at risk for HPV-related disease, especially when they are not having sex, or are in monogamous marital relationships $[94,95,99,106,108]$. The lack of awareness of HPV transmission and health risks may be exacerbated by the length of time from infection to disease. In strongly male-dominated societies, values of shame and honour prevent women's matters, including female anatomy and STIs, from being openly discussed and define 'modest womanhood' [115]. These are powerful social barriers to effective dialogue about HPV and cancer. Indian physicians, for example, are reluctant to discuss STIs and prophylaxis with female patients or their families and see HPV immunization as an unnecessary addition to already heavy caseloads [110].

The integration of screening and immunization into public health education is critical to efforts to control cervical cancer [116]. The evidence generated by KAB 
Table 1 From Laboratories to People: Barriers in HPV vaccine implementation

\begin{tabular}{|c|c|c|c|}
\hline INNOVATION & PROCUREMENT AND DELIVERY & POLICY FORMULATION & $\begin{array}{l}\text { SOCIAL CHALLENGES } \\
\text { (Knowledge, attitudes, beliefs) }\end{array}$ \\
\hline Patent monopolies [19]. & $\begin{array}{l}\text { Inadequate regulatory mechanisms, resources } \\
\text { and infrastructure, i.e., for reporting of adverse } \\
\text { events and post-market surveillance }[23,129] \text {. }\end{array}$ & High vaccine costs [18]. & $\begin{array}{l}\text { Parents and adolescents } \\
\text { [94-97,99-109] }\end{array}$ \\
\hline $\begin{array}{l}\text { Scarcity of instruments and } \\
\text { models for technology transfer } \\
\text { of inexpensive biogenerics } \\
{[19,21] \text {. }}\end{array}$ & $\begin{array}{l}\text { Cold chain issues, preventing quality- assured } \\
\text { and controlled transportation and storage of } \\
\text { vaccines }[23,129] \text {. }\end{array}$ & $\begin{array}{l}\text { Competing health priorities } \\
\text { (e.g., HIV/AIDS, malaria) [105]. }\end{array}$ & $\begin{array}{l}\text { Perceived low HPV/STI } \\
\text { susceptibility. }\end{array}$ \\
\hline \multirow[t]{12}{*}{$\begin{array}{l}\text { Gaps in multilateral funding for } \\
\text { vaccine procurement [20]. }\end{array}$} & & $\begin{array}{l}\text { Controversies over HPV } \\
\text { vaccine mandates } \\
\text { [64-66,86,89-91]. }\end{array}$ & $\begin{array}{l}\text { Unwillingness to discuss sex and } \\
\text { STI. }\end{array}$ \\
\hline & & $\begin{array}{l}\text { Inadequate knowledge } \\
\text { exchange about STI risks and } \\
\text { need for prevention } \\
{[110,113,114] \text {. }}\end{array}$ & $\begin{array}{l}\text { Perceived inappropriateness for } \\
\text { pre-adolescents. }\end{array}$ \\
\hline & & & Stigma, loss of privacy. \\
\hline & & & $\begin{array}{l}\text { Concerns about adolescent } \\
\text { promiscuity and beliefs in moral } \\
\text { education and marital } \\
\text { monogamy. }\end{array}$ \\
\hline & & & $\begin{array}{l}\text { Suspicion of commercial motives } \\
\text { and unethical vaccine trials. }\end{array}$ \\
\hline & & & $\begin{array}{l}\text { Worry about vaccine ingredients } \\
\text { and adverse effects. }\end{array}$ \\
\hline & & & Needle fears. \\
\hline & & & $\begin{array}{l}\text { Gaps in availability and access. } \\
\text { Competing life priorities and } \\
\text { pressures. }\end{array}$ \\
\hline & & & $\begin{array}{l}\text { Vaccine costs and duration of } \\
\text { effectiveness. }\end{array}$ \\
\hline & & & Healthcare providers $[98,110]$ \\
\hline & & & $\begin{array}{l}\text { Unwillingness to endorse } \\
\text { vaccine, discuss sex and STI, or } \\
\text { to stock vaccine }\end{array}$ \\
\hline & & & $\begin{array}{l}\text { Lack of personnel and facilities } \\
\text { for vaccination and heavy case } \\
\text { loads in clinics. }\end{array}$ \\
\hline
\end{tabular}

studies needs to be translated into community-based programs about the risks of HPV and the need to take action against it. Text-heavy or hard-to-access webbased information will not reach the illiterate or those without computers [113]. Simple messages through lowcost outreach strategies (e.g., street theater, door-todoor visits by community workers, discussions at markets and bus stops) could more effectively engage the community $[113,117]$. Messaging must convey that both men and women are sufferers and carriers of HPV and that HPV is neither an exclusively female problem nor a matter of shame for women. Information about HPV and cervical cancer need to target males, who in traditional societies are often key decision makers, even in deciding women's visits to clinics $[95,103,107,108,112]$.

HPV immunization: Comparing implementation scenarios Internationally, the implementation of HPV immunization has had a variety of outcomes, associated with a constellation of factors affecting health practicalities, policies and priorities.

Australia, Canada and the UK have publicly funded programs that provide HPV immunization for peri-adolescent girls through school based and catch-up programs $[80,118,119]$. In the EU countries offering subsidized HPV immunization, funding modalities and target populations are heterogeneous $[120,121]$. Vaccine delivery in the EU is school-based, or on-demand from general practitioners or public health clinics, with or without a letter of invitation $[120,121]$. While the vaccine is offered through public health systems in Denmark, France, Germany, Italy, Spain, the Netherlands, and the UK, the Austrian government decided against including the vaccine in publicly funded immunization programs. They reasoned that it would not be as cost-effective as Pap testing; even with a high and sustained uptake among both boys and girls, there would be no appreciable reductions in cervical cancer for many decades [121]. In the UK, reduced acceptability of the 
HPV vaccine may have been affected by the nowdebunked link between autism and Measles-MumpsRubella (MMR) vaccine [121]. Few Eastern European countries have adopted HPV into their national immunization programs. These countries also lack organized screening programs, possibly indicating their lack of resources [16].

In the US, HPV immunization is available outside the school system. Uninsured adolescents in the age-eligible cohort can obtain the vaccine free of cost through the VFC program [89]. For others, HPV immunization depends either on individual ability to buy the vaccine or on the extent of insurance coverage. There are no established guidelines or standards for adolescents' visits to doctors. Adolescents are confronted by waning immunity as well as poorer compliance with clinic visits required by multi-dose schedules $[117,122,123]$. In Canada, HPV immunization is delivered as part of the standard school vaccine formulary through public-health mechanisms to girls in Grades 7 and 8 [124]. Immunization requires informed and voluntary parental consent [125]. According to Canada's National Advisory Committee on Immunization (NACI), a rationale for targeting Grade 7 girls for HPV immunization is that school-dropouts and sexual activity are still relatively limited in that cohort [2]. In Canada, HPV immunization is delivered alongside accepted and normalized vaccines (e.g., HBV) through established public-health systems $[92,124,125]$. This integration of HPV vaccine into existing delivery systems may have softened the controversy and operational problems of a federally-directed vaccine roll-out, whose speed precluded prior consultation and knowledge-sharing with Canadian stakeholders at the provincial and territorial levels [77,126,127].

In developing countries, HPV vaccines are not offered as part of national immunization schedules. Immunization costs are not covered and vaccine uptake may be determined by the market (and marketing). Although school-based delivery platforms have a good performance record and are relatively equitable, they may have less success in many developing countries. Even where schools are available, young girls are often unable to attend due to obligations both in and outside the home. These programs also bypass street-dwelling youth in developing and advanced economies [128]. Catch-up immunization programs are only marginally successful. Mandatory HPV immunization, although effective, would strain the health budgets of developing countries.

\section{Conclusion}

Although HPV vaccines represent a promising biological innovation, they will yield the greatest public health benefits only when introduced at affordable prices into a context of robust healthcare infrastructure. Determining which vaccines to include in a public health program requires capacity-intensive infrastructure for the regulation, production, and post-market surveillance of vaccines [129]. In the event that HPV vaccines become available at lower prices in developing countries, gaps in capacity in these countries lends difficulties to effective decision-making, delivery, and surveillance.

HPV vaccine remains unavailable to poor and vulnerable women. Those most able to access HPV immunization may be also those more able to access cervical screening [80]. The result is a widening of health disparities, in both developing and developed countries. Socioeconomic inequalities persist in the inability of vulnerable women to access health services, even in countries with a national health service. As competition reduces costs and HPV vaccines become accessible in poorer regions, it will remain important for individuals, communities and health care providers to engage in dialogue about HPV transmission, risks, disease, and prevention through cervical screening as well as immunization.

\section{Additional material}

Additional file 1: Appendix. The data file is a word file containing an explanatory appendix with a statement regarding the use of a proprietary term.

List of Abbreviations used

ACIP: Advisory Committee on Immunization Practices; ACOG: American Congress of Obstetricians and Gynecologists; AEFI: Adverse Events Following Immunization; ASCUS: Atypical Squamous Cells of Undisclosed Significance; EPI: Expanded Program in Immunization; EU: European Union; FDA: Food and Drugs Administration; GAVI: Global Alliance for Vaccines Initiative; HBV: Hepatitis B Virus; HIV: Human Immunodeficiency Virus; HPV: Human Papillomavirus; HSV: Herpes Simplex Virus; KAB: Knowledge, Attitudes and Behavior; LBC: Liquid-Based Cytology; LGBT: Lesbian, Gay, Bisexual and Transgender; STI: Sexually transmitted infections; VIA: Visual Inspection with Acetic Acid; VILI: Visual Inspection with Lugol's lodine; WHO: World Health Organization.

\section{Acknowledgements and Funding}

This work was supported by the Canadian Institutes of Health Research (Catalyst Grant CVC-99978). This project, 'Regulatory challenges to the development of new vaccines: Mapping emergent relations between science, evidence and policy' was approved by the Research Ethics Board of the IWK Health Centre, Halifax, Nova Scotia, Canada. The authors are grateful to the peer reviewers for their critical inputs and to Prof Noni MacDonald of the Canadian Center for Vaccinology, IWK Health Center, Halifax, Nova Scotia, Canada for comments on early drafts of the manuscript.

\section{Author details}

1Department of Bioethics, Dalhousie University, Faculty of Medicine, 1459 Oxford Street, Halifax, Nova Scotia, B3H 4R2, Canada. ${ }^{2}$ Technoscience and Regulation Research Unit, 1459 Oxford Street, Halifax, Nova Scotia, B3H 4R2, Canada.

\section{Authors' contributions}

AM and JG conceptualized and designed the study. AM selected the literature and drafted the manuscript. JG revised the manuscript. AM and JG read and approved the final manuscript. 


\section{Authors' information}

JG is Professor and Canada Research Chair in Bioethics, and Professor of Pediatrics (Division of Infectious Diseases) in the Faculty of Medicine at Dalhousie University. She is a medical anthropologist who draws upon epidemiology and technology assessment to study cultural, technical and moral issues related to health and the regulation of biotechnologies. She currently studies new and emerging vaccines, including vaccines against HPV, pandemic influenza, and the conjugate meningitis A vaccine for subSaharan Africa.

AM is a sociologist and a Postdoctoral Research Fellow at the Technoscience and Regulation Research Unit, Faculty of Medicine, Dalhousie University, Canada. Her current project The Administration of a Quadrivalent HPV Vaccine for Minors' is funded by the Canadian Institutes of Health Research $(\mathrm{ClHR})$ and examines knowledge, attitudes and practices in HPV immunization in Nova Scotia, Canada.

\section{Competing interests}

The authors declare that they have no competing interests.

Received: 15 December 2010 Accepted: 30 June 2011 Published: 30 June 2011

\section{References}

1. Koulova A, Tsui J, Irwin K, Van Damme P, Biellik R, Aguado MT: Country recommendations on the inclusion of HPV vaccines in national immunization programmes among high-income countries, June 2006January 2008. Vaccine 2008, 26:6529-41.

2. National Advisory Committee on Immunization (NACl): Statement on Human Papillomavirus Vaccine. [http://www.phac-aspc.gc.ca/publicat/ccdrrmtc/07pdf/acs33-02.pdf].

3. Markowitz LE, Dunne EF, Saraiya M, Lawson HW, Chesson H, Unger ER, Centers for Disease Control and Prevention (CDC); Advisory Committee on Immunization Practices (ACIP): Quadrivalent Human Papillomavirus Vaccine: Recommendations of the Advisory Committee on Immunization Practices (ACIP). MMWR Recomm Rep 2007, 56(RR-2):1-24.

4. Foerster V, Murtagh J: Human papillomavirus (HPV) vaccines: a Canadian update. Issues Emerg Health Technol 2007, 109:1-8.

5. Monie A, Hung CF, Roden R, Wu TC: Cervarix: a vaccine for the prevention of HPV 16, 18-associated cervical cancer. Biologics 2008, 2:97-105.

6. Centers for Disease Control and Prevention (CDC): FDA licensure of bivalent human papillomavirus vaccine (HPV2, Cervarix) for use in females and updated HPV vaccination recommendations from the advisory committee on immunization practices (ACIP). Morbidity and Mortality Weekly Report (MMWR) 2010, 59:626-629.

7. Centers for Disease Control and Prevention (CDC): FDA licensure of quadrivalent human papillomavirus vaccine (HPV4, Gardasil) for use in males and guidance from the Advisory Committee on Immunization Practices (ACIP). Morbidity and Mortality Weekly Report (MMWR) 2010, 59:630-2.

8. Schiller JT, Castellsagué X, Villa LL, Hildesheim A: An update of prophylactic human papillomavirus L1 virus-like particle vaccine clinical trial results. Vaccine 2008, 26(Suppl 10):K53-61.

9. Fisher R, Darrow DH, Tranter M, Williams JV: Human papillomavirus vaccine: recommendations, issues and controversies. Curr Opin Pediatr 2008, 20:441-5.

10. Garland SM, Smith JS: Human papillomavirus vaccines: current status and future prospects. Drugs 2010, 70:1079-98.

11. Frazer $\mid \mathrm{H}$ : Measuring serum antibody to human papillomavirus following infection or vaccination. Gynecol Oncol 2010, 118(Suppl 1):S8-11.

12. FUTURE I/II Study Group, Dillner J, Kjaer SK, Wheeler CM, Sigurdsson K, Iversen OE, Hernandez-Avila M, Perez G, Brown DR, Koutsky LA, Tay EH, García P, Ault KA, Garland SM, Leodolter S, Olsson SE, Tang GW, Ferris DG, Paavonen J, Lehtinen M, Steben M, Bosch FX, Joura EA, Majewski S, Muñoz N, Myers ER, Villa LL, Taddeo FJ, Roberts C, Tadesse A, Bryan JT, Maansson R, Lu S, Vuocolo S, Hesley TM, Barr E, Haupt R: Four year efficacy of prophylactic human papillomavirus quadrivalent vaccine against low grade cervical, vulvar, and vaginal intraepithelial neoplasia and anogenital warts: randomised controlled trial. BMJ 2010, 341:C3493.

13. Harper DM: Prevention of human papillomavirus infections and associated diseases by vaccination: a new hope for global public health. Public Health Genomics 2009, 12:319-30.
14. Lowy DR, Solomon D, Hildesheim A, Schiller JT, Schiffman M: Human papillomavirus infection and the primary and secondary prevention of cervical cancer. Cancer 2008, 113(Suppl 7):1980-93.

15. Wright TC, Van Damme P, Schmitt HJ, Meheus A: Chapter 14: HPV vaccine introduction in industrialized countries. Vaccine 2006, 24(Suppl 3):122-31.

16. Lévy-Bruhl D, Bousquet V, King LA, O'Flanagan D, Bacci S, Lopalco PL, Salmaso S, country specific VENICE gate keepers and contact points: The current state of introduction of HPV vaccination into national immunisation schedules in Europe: results of the VENICE 2008 survey. Eur J Cancer 2009, 45:2709-13.

17. International Monetary Fund: World Economic Outlook Database-WEO Groups and Aggregates Information, Country Composition of WEO Groups [http://www.imf.org/external/pubs/ft/weo/2010/01/weodata/groups. htm\#oem].

18. Agosti JM, Goldie SJ: Introducing HPV vaccine in developing countrieskey challenges and issues. N Engl J Med 2007, 356:1908-10.

19. Maybarduk P, Rimmington S: Compulsory Licenses: A Tool to Improve Global Access to the HPV Vaccine? Am J Law Med 2009, 35:323-350.

20. Andrus JK, Sherris J, Fitzsimmons JW, Kane MA, Aguado MT: Introduction of human papillomavirus vaccines into developing countries international strategies for funding and procurement. Vaccine 2008, 26(Suppl 10):K87-92.

21. Padmanabhan S, Amin T, Sampat B, Cook-Deegan R, Chandrasekharan S: Intellectual property, technology transfer and manufacture of low-cost HPV vaccines in India. Nat Biotechnol 2010, 28:671-8.

22. Graham J, Jones M: Rendre evident: une approche symetrique de la réglementation des produits thérapeutiques. (Determining evidence: a symmetrical approach to the regulation of therapeutic products.). Sociologie et sociétés 2010, 42:153-180.

23. Erickson $L$, De Wals $P$, Farand $L:$ An analytical framework for immunization programs in Canada. Vaccine 2005, 23:2470-6.

24. Boutayeb A, Boutayeb S: The burden of non communicable diseases in developing countries. Int J Equity Health 2005, 4:2.

25. Tsu VD: Overcoming barriers and ensuring access to HPV vaccines in low-income countries. Am J Law Med 2009, 35:401-13.

26. WHO/ICO Information Centre on HPV and Cervical Cancer (HPV Information Centre): Human Papillomavirus and Related Cancers in World. Summary Report 2010 [http://apps.who.int/hpvcentre/statistics/dynamic/ico/ SummaryReportsSelect.cfm]

27. Muñoz N, Bosch FX, Castellsagué X, Díaz M, de Sanjose S, Hammouda D, Shah KV, Meijer CJ: Against which human papillomavirus types shall we vaccinate and screen? The international perspective. Int J Cancer 2004, 111:278-85.

28. Franco EL, Harper DM: Vaccination against human papillomavirus infection: a new paradigm in cervical cancer control. Vaccine 2005, 23:2388-94.

29. Cutts FT, Franceschi S, Goldie S, Castellsague X, de Sanjose S, Garnett G, Edmunds WJ, Claeys P, Goldenthal KL, Harper DM, Markowitz L: Human papillomavirus and HPV vaccines: a review. Bull World Health Organ 2007, 85:719-26

30. Galani E, Christodoulou C: Human papilloma viruses and cancer in the post-vaccine era. Clin Microbiol Infect 2009, 15:977-81.

31. Stanley M: Potential mechanisms for HPV vaccine-induced long-term protection. Gynecol Oncol 2010, 118(1 Suppl):S2-7.

32. Sankaranarayanan R, Gaffikin L, Jacob M, Sellors J, Robles S: A critical assessment of screening methods for cervical neoplasia. Int I Gynaecol Obstet 2005, 89(Suppl 2):S4-S12.

33. American Society for Colposcopy and Cervical Pathology: HPV Genotyping Clinical Update [http://www.asccp.org/pdfs/consensus/ clinical_update_20090408.pdf].

34. Jones BA, Davey DD: Quality management in gynecologic cytology using interlaboratory comparison. Arch Pathol Lab Med 2000, 124:672-81.

35. Sankaranarayanan R, Bhatla N, Gravitt PE, Basu P, Esmy PO, Ashrafunnessa KS, Ariyaratne Y, Shah A, Nene BM: Human papillomavirus infection and cervical cancer prevention in India, Bangladesh, Sri Lanka and Nepal. Vaccine 2008, 26(Suppl 12):M43-52.

36. Othman NH, Rebolj M: Challenges to cervical screening in a developing country: The case of Malaysia. Asian Pac J Cancer Prev 2009, 10:747-52.

37. Tay SK, Ngan HY, Chu TY, Cheung AN, Tay EH: Epidemiology of human papillomavirus infection and cervical cancer and future perspectives in Hong Kong, Singapore and Taiwan. Vaccine 2008, 26(Suppl 12):M60-70. 
38. Scarinci IC, Garcia FA, Kobetz E, Partridge EE, Brandt HM, Bell MC, Dignan M, Ma GX, Daye JL, Castle PE: Cervical cancer prevention: new tools and old barriers. Cancer 2010, 116:2531-42.

39. Manderson L, Hoban E: Cervical cancer services for Indigenous women: advocacy, community-based research and policy change in Australia. Women Health 2006, 43:69-88.

40. Elkan R, Avis M, Cox K, Wilson E, Patel S, Miller S, Deepak N, Edwards C, Staniszewska S, Kai J: The reported views and experiences of cancer service users from minority ethnic groups: a critical review of the literature. Eur J Cancer Care 2007, 16:109-21.

41. McDonald JT, Kennedy S: Cervical cancer screening by immigrant and minority women in Canada. J Immigr Minor Health 2007, 9:323-34.

42. Johnson CE, Mues KE, Mayne SL, Kiblawi AN: Cervical cancer screening among immigrants and ethnic minorities: a systematic review using the Health Belief Model. J Low Genit Tract Dis 2008, 12:232-41.

43. Amankwah $\mathrm{E}$, Ngwakongnwi $\mathrm{E}$, Quan $\mathrm{H}$ : Why many visible minority women in Canada do not participate in cervical cancer screening. Ethn Health 2009, 14:337-49.

44. Ma GX, Toubbeh Jl, Wang MQ, Shive SE, Cooper L, Pham A: Factors associated with cervical cancer screening compliance and noncompliance among Chinese, Korean, Vietnamese, and Cambodian women. J Natl Med Assoc 2009, 101:541-51.

45. Samuel PS, Pringle JP, James NW, Fielding SJ, Fairfield KM: Breast, cervical, and colorectal cancer screening rates amongst female Cambodian, Somali, and Vietnamese immigrants in the USA. Int J Equity Health 2009, 8:30.

46. ACOG Committee on Practice Bulletins-Gynecology: ACOG Practice Bulletin no. 109: Cervical cytology screening. Obstet Gynecol 2009, 114:1409-20.

47. Clarke $A E$, Casper M: From simple technology to complex arena: classification of Pap smears, 1917-90. Med Anthropol Q 1996, 10:601-23.

48. National Cancer Institute Workshop: The 1988 Bethesda System for reporting cervical/vaginal cytological diagnoses. JAMA 1989, 262:931-4.

49. Report of the 1991 Bethesda workshop: The revised Bethesda System for reporting cervical/vaginal cytologic diagnoses. Acta Cytol 1992, 36:273-6.

50. McLachlin CM, Mai V, Murphy J, Fung-Kee-Fung M, Chambers A, Oliver TK: Ontario cervical cancer screening clinical practice guidelines. J Obstet Gynaecol Can 2007, 29:344-53.

51. Sawaya GF: Cervical-cancer screening-new guidelines and the balance between benefits and harms. N Engl J Med 2009, 361:2503-5.

52. World Health Organization: Cytology screening. [http://www.who.int/ cancer/detection/cytologyscreen/en/index.html].

53. Kitchener HC, Castle PE, Cox JT: Chapter 7: Achievements and limitations of cervical cytology screening. Vaccine 2006, 24:63-70.

54. Franco EL, Coutlée F, Ferenczy A: Integrating human papillomavirus vaccination in cervical cancer control programmes. Public Health Genomics 2009, 12:352-61.

55. Zhao FH, Lin MJ, Chen F, Hu SY, Zhang R, Belinson JL, Sellors JW, Franceschi S, Qiao YL, Castle PE, on behalf of Cervical Cancer Screening Group in China: Performance of high-risk human papillomavirus DNA testing as a primary screen for cervical cancer: a pooled analysis of individual patient data from 17 population-based studies from China. Lancet Oncol 2010.

56. Sankaranarayanan R, Basu P, Wesley RS, Mahe C, Keita N, Mbalawa CC Sharma R, Dolo A, Shastri SS, Nacoulma M, Nayama M, Somanathan T, Lucas E, Muwonge R, Frappart L, Parkin DM: Accuracy of visual screening for cervical neoplasia: Results from an IARC multicentre study in India and Africa. Int J Cancer 2004, 110:907-13.

57. Chirenje ZM, Rusakaniko S, Kirumbi L, Ngwalle EW, Makuta-Tlebere P, Kaggwa S, Mpanju-Shumbusho W, Makoae L: Situation analysis for cervical cancer diagnosis and treatment in east, central and southern African countries. Bull World Health Organ 2001, 79:127-32, 18.

58. Boutayeb A: Developing countries and neglected diseases: challenges and perspectives. Int J Equity Health 2007, 6:20.

59. Anorlu Rl: Cervical cancer: the sub-Saharan African perspective. Reprod Health Matters 2008, 16:41-9.

60. Hanna TP, Kangolle AC: Cancer control in developing countries: using health data and health services research to measure and improve access, quality and efficiency. BMC Int Health Hum Rights 2010, 10:24.

61. Sankaranarayanan R, Thara S, Esmy PO, Basu P: Cervical cancer: screening and therapeutic perspectives. Med Princ Pract 2008, 17:351-64.
62. Casper MJ, Carpenter LM: Sex, drugs, and politics: the HPV vaccine for cervical cancer. Sociol Health Illn 2008, 30:886-99.

63. Colgrove J, Abiola S, Mello MM: HPV vaccination mandates-lawmaking amid political and scientific controversy. N Engl J Med 2010, 363:785-91.

64. Haber G, Malow RM, Zimet GD: The HPV vaccine mandate controversy. J Pediatr Adolesc Gynecol 2007, 20:325-31.

65. Aronowitz R: Gardasil: A Vaccine Against Cancer and a Drug to reduce risk. In Three shots at prevention: The HPV vaccine and the politics of medicine's simple solutions.. 1 edition. Edited by: Wailoo, K, Livingston J, Epstein S, Aronowitz R. Baltimore: Johns Hopkins University Press; 2010:21-38,

66. Hunt A, Connell E: The HPV vaccination campaign: A project of moral regulation in an era of biopolitics. Can J Sociol 2010, 35:1, 63-82.

67. Phillips SP: Defining and measuring gender: A social determinant of health whose time has come. Int J Equity Health 2005, 4:11.

68. Frazer I: Human Papillomaviruses. In Vaccines: A biography. Edited by: Artenstein AW. New York: Springer; 2010:

69. Tjalma WA, Arbyn M, Paavonen J, van Waes TR, Bogers JJ: Prophylactic human papillomavirus vaccines: the beginning of the end of cervical cancer. Int J Gynecol Cancer 2004, 14:751-61.

70. Leggatt GR, Frazer IH: HPV vaccines: the beginning of the end for cervical cancer. Curr Opin Immunol 2007, 19:232-8.

71. Zimet GD, Liddon N, Rosenthal SL, Lazcano-Ponce E, Allen B: Chapter 24: Psychosocial aspects of vaccine acceptability. Vaccine 2006, 24(Suppl 3):201-9.

72. Habel MA, Liddon N, Stryker JE: The HPV vaccine: a content analysis of online news stories. J Womens Health (Larchmt) 2009, 18:401-7.

73. Hughes J, Cates JR, Liddon N, Smith JS, Gottlieb SL, Brewer NT: Disparities in how parents are learning about the human papillomavirus vaccine. Cancer Epidemiol Biomarkers Prev 2009, 18:363-72.

74. Kelly BJ, Leader AE, Mittermaier DJ, Hornik RC, Cappella JN: The HPV vaccine and the media: how has the topic been covered and what are the effects on knowledge about the virus and cervical cancer? Patient Educ Couns 2009, 77:308-13.

75. Forster A, Wardle J, Stephenson J, Waller J: Passport to promiscuity or lifesaver: press coverage of HPV vaccination and risky sexual behavior. J Health Commun 2010, 15:205-17.

76. Hilton S, Hunt K, Langan M, Bedford H, Petticrew M: Newsprint media representations of the introduction of the HPV vaccination programme for cervical cancer prevention in the UK (2005-2008). Soc Sci Med 2010, 70:942-50.

77. Mah CL: Governing Immunization in Canada. PhD Thesis University of Toronto, Department of Health Policy, Management and Evaluation; 2009, 138-145 [https://tspace.library.utoronto.ca/bitstream/1807/19058/1/ Mah_Catherine_L_200911_PhD_thesis.pdf], [Chapters 7-8].

78. Epstein S: The Great Undiscussable: HPV, Anal Cancer and Gay Men's Health. In Three shots at prevention: The HPV va ccine and the politics of medicine's simple solutions.. 1 edition. Edited by: Wailoo K, Livingston J, Epstein S, Aronowitz R. Baltimore: Johns Hopkins University Press; 2010:61-90.

79. Mayer KH, Bradford JB, Makadon HJ, Stall R, Goldhammer H, Landers S: Sexual and gender minority health: what we know and what needs to be done. Am J Public Health 2008, 98:989-95.

80. Crosbie EJ, Brabin L: Cervical cancer: problem solved? Vaccinating girls against human papillomavirus. BJOG 2010, 117:137-42.

81. Adams M, Jasani B, Fiander A: Human papilloma virus (HPV) prophylactic vaccination: challenges for public health and implications for screening. Vaccine 2007, 25:3007-13.

82. Howlett RI, Miller $A B$, Pasut $G$, Mai V: Defining a strategy to evaluate cervical cancer prevention and early detection in the era of HPV vaccination. Prev Med 2009, 48:432-7.

83. Stanley M, Villa LL: Monitoring HPV vaccination. Vaccine 2008, 26(Suppl 1): A24-7.

84. Bonanni P, Cohet C, Kjaer SK, Latham NB, Lambert PH, Reisinger K, Haupt RM: A summary of the post-licensure surveillance initiatives for Gardasil/Silgard. Vaccine 2010, 28:4719-30.

85. Black AD, Car J, Pagliari C, Anandan C, Cresswell K, Bokun T, McKinstry B, Procter R, Majeed A, Sheikh A: The Impact of eHealth on the Quality and Safety of Health Care: A Systematic Overview. PLoS Med 2011, 8 : e1000387. 
86. Heffernan ME, Garland SM, Kane MA: Global reduction of cervical cancer with human papillomavirus vaccines: insights from the hepatitis $B$ virus vaccine experience. Sex Health 2010, 7:383-90.

87. Coates RA, Rankin JG: Cost without benefit? The introduction of hepatitis B vaccine in Canada. Can Med Assoc J 1983, 128:1158-60.

88. Kane MA: Global implementation of human papillomavirus (HPV) vaccine: lessons from hepatitis B vaccine. Gynecol Oncol 2010, 117(2): S32-5.

89. Dickerson JB, Smith ML, Ory MG: Increasing uptake of Gardasil among American adolescents: Comparisons with the history of Hepatitis B vaccination. Hum Vaccin 2011.

90. Rothman SM, Rothman DJ: Marketing HPV vaccine: implications for adolescent health and medical professionalism. JAMA 2009, 302:781-6.

91. Livingston J, Epstein S, Aronowitz R: Vaccine Timelines. In Three shots at prevention: The HPV vaccine and the politics of medicine's simple solutions.. 1 edition. Edited by: Wailoo K, Livingston J, Epstein S, Aronowitz R. Baltimore: Johns Hopkins University Press; 2010:xix-xxx.

92. Scheifele D: Universal childhood hepatitis B vaccination: infants vs. preadolescents, the Canadian perspective. Pediatr Infect Dis J 1998, 17(Suppl 7):S35-7.

93. Marra F, Cloutier K, Oteng B, Marra C, Ogilvie G: Effectiveness and cost effectiveness of human papillomavirus vaccine: a systematic review. Pharmacoeconomics 2009, 27:127-47.

94. Friedman $A L$, Shepeard $\mathrm{H}$ : Exploring the knowledge, attitudes, beliefs, and communication preferences of the general public regarding HPV: findings from CDC focus group research and implications for practice. Health Educ Behav 2007, 34:471-85.

95. Lee PW, Kwan TT, Tam KF, Chan KK, Young PM, Lo SS, Cheung AN, Ngan HY: Beliefs about cervical cancer and human papillomavirus (HPV) and acceptability of HPV vaccination among Chinese women in Hong Kong. Prev Med 2007, 45:130-4.

96. Rosenthal D, Dyson S, Pitts M, Garland S: Challenges to accepting a human papilloma virus (HPV) vaccine: a qualitative study of Australian women. Women Health 2007, 45:59-73.

97. Scarinci IC, Garcés-Palacio IC, Partridge EE: An examination of acceptability of HPV vaccination among African American women and Latina immigrants. J Womens Health (Larchmt) 2007, 16:1224-33.

98. Keating KM, Brewer NT, Gottlieb SL, Liddon N, Ludema C, Smith JS: Potential barriers to HPV vaccine provision among medical practices in an area with high rates of cervical cancer. J Adolesc Health 2008, 43(Suppl 4):S61-7.

99. Kwan TT, Chan KK, Yip AM, Tam KF, Cheung AN, Young PM, Lee PW, Ngan HY: Barriers and facilitators to human papillomavirus vaccination among Chinese adolescent girls in Hong Kong: a qualitative-quantitative study. Sex Transm Infect 2008, 84:227-32.

100. Toffolon-Weiss M, Hagan K, Leston J, Peterson L, Provost E, Hennessy T: Alaska Native parental attitudes on cervical cancer, HPV and the HPV vaccine. Int J Circumpolar Health 2008, 67:363-73.

101. Vanslyke JG, Baum J, Plaza V, Otero M, Wheeler C, Helitzer DL: HPV and cervical cancer testing and prevention: knowledge, beliefs, and attitudes among Hispanic women. Qual Health Res 2008, 18:584-96.

102. Bair RM, Mays RM, Sturm LA, Zimet GD: Acceptability of the human papillomavirus vaccine among Latina mothers. J Pediatr Adolesc Gynecol 2008, 21:329-34.

103. Bingham A, Drake JK, LaMontagne DS: Sociocultural issues in the introduction of human papillomavirus vaccine in low-resource settings. Arch Pediatr Adolesc Med 2009, 163:455-61.

104. Do H, Seng P, Talbot J, Acorda E, Coronado GD, Taylor VM: HPV vaccine knowledge and beliefs among Cambodian American parents and community leaders. Asian Pac J Cancer Prev 2009, 10:339-44.

105. Harries J, Moodley J, Barone MA, Mall S, Sinanovic E: Preparing for HPV vaccination in South Africa: key challenges and opinions. Vaccine 2009, 27:38-44.

106. Katz ML, Reiter PL, Heaner S, Ruffin MT, Post DM, Paskett ED: Acceptance of the HPV vaccine among women, parents, community leaders, and healthcare providers in Ohio Appalachia. Vaccine 2009, 27:3945-52.

107. Madhivanan P, Krupp K, Yashodha MN, Marlow L, Klausner JD, Reingold AL: Attitudes toward HPV vaccination among parents of adolescent girls in Mysore, India. Vaccine 2009, 27:5203-8.
108. Marlow LA, Wardle J, Waller J: Attitudes to HPV vaccination among ethnic minority mothers in the UK: an exploratory qualitative study. Hum Vaccin 2009, 5:105-10.

109. Wong LP: HPV information needs, educational messages and channel of delivery preferences: views from developing country with multiethnic populations. Vaccine 2009, 27:1410-5.

110. Krupp K, Marlow LA, Kielmann K, Doddaiah N, Mysore S, Reingold AL, Madhivanan P: Factors associated with intention-to-recommend human papillomavirus vaccination among physicians in Mysore, India. J Adolesc Health 2010, 46:379-84

111. Kaler A: Health interventions and the persistence of rumour: the circulation of sterility stories in African public health campaigns. Soc Sci Med 2009, 68:1711-9.

112. Dugas M, Dubé E, Kouyaté B, Sanou A, Bibeau G: Portrait of a lengthy vaccination trajectory in Burkina Faso: from cultural acceptance of vaccines to actual immunization. BMC Int Health Hum Rights 2009, 9(Suppl 1):S9.

113. Sherris J, Friedman A, Wittet S, Davies P, Steben M, Saraiya M: Chapter 25: Education, training, and communication for HPV vaccines. Vaccine 2006, 24(Suppl 3):210-8.

114. Program for Appropriate Technology in Health (PATH): Introducing HPV vaccines in developing countries: overcoming the challenges. [http:// www.path.org/files/RH_hpv_intro.pdf].

115. McCarthy C: Toward a Definition of Interiority. Space and Culture; 2005:8:112-125.

116. Stanley M: Human papillomavirus vaccines versus cervical cancer screening. Clin Oncol (R Coll Radiol) 2008, 20:388-94.

117. Mackroth MS, Irwin K, Vandelaer J, Hombach J, Eckert LO: Immunizing school-age children and adolescents: experience from low- and middleincome countries. Vaccine 2010, 28:1138-47.

118. Ogilvie GS, Remple VP, Marra F, McNeil SA, Naus M, Pielak KL, Ehlen TG, Dobson SR, Money DM, Patrick DM: Parental intention to have daughters receive the human papillomavirus vaccine. CMAJ 2007, 177:1506-12.

119. Watson M, Shaw D, Molchanoff L, Mclnnes C: Challenges, lessons learned and results following the implementation of a human papilloma virus school vaccination program in South Australia. Aust N Z J Public Health 2009, 33:365-70.

120. European Cervical Cancer Association (ECCA): HPV Vaccination Across Europe. [http://www.ecca.info/fileadmin/user_upload/HPV_Vaccination/ ECCA_HPV_Vaccination_April_2009.pdf].

121. Stöckl A: Public discourses and policy making: the HPV vaccination from the European perspective. In Three shots at prevention: The HPV vaccine and the politics of medicine's simple solutions. 1 edition. Edited by: Wailoo K, Livingston J, Epstein S, Aronowitz R. Baltimore: Johns Hopkins University Press; 2010:254-269.

122. Humiston SG, Rosenthal SL: Challenges to vaccinating adolescents: vaccine implementation issues. Pediatr Infect Dis J 2005, 24:S134-40.

123. Hernandez G, Nestor C: Educating teens about vaccines. J Pediatr Health Care 2006, 20:342-9.

124. Department of Health and Wellness: HPV Immunization Launched. [http:// www.gov.ns.ca/news/details.asp?id=20070620002].

125. Department of Health and Wellness: School Immunization Schedule. [http://www.gov.ns.ca/hpp/publications/13153_Schoollmmunization Schedule_En.pdf].

126. Lippman A, Melnychuk R, Shimmin C, Boscoe M: Human papillomavirus, vaccines and women's health: questions and cautions. CMAJ 2007, 177:484-7.

127. Haas M, Ashton T, Blum K, Christiansen T, Conis E, Crivelli L, Lim MK, Lisac M, Macadam M, Schlette S: Drugs, sex, money and power: an HPV vaccine case study. Health Policy 2009, 92:288-95.

128. MacDonald N, Hébert PC: Human papillomavirus vaccine: waiting for a miracle. CMAJ 2007, 177:433-435.

129. Franco EL, Bosch FX, Cuzick J, Schiller JT, Garnett GP, Meheus A, Wright TC: Chapter 29: Knowledge gaps and priorities for research on prevention of HPV infection and cervical cancer. Vaccine 2006, 24:S3/242-9.

doi:10.1186/1475-9276-10-27

Cite this article as: Graham and Mishra: Global challenges of

implementing human papillomavirus vaccines. International Journal for Equity in Health 2011 10:27. 